\title{
The Use of Cognate Words and Interlingual Homographs to Investigate the Cross-Linguistics in Second Language Processing in Iran
}

\author{
Javad Gholami, Parviz Alavinia, Siros Izadpanah
}

Urmia University, Urmia, Iran

\begin{abstract}
Various investigations have shown that the native language impacts foreign word recognition and this influence is adapted by the dexterity in the nonnative language. Cognates, words which area like beyond two or additional languages in some fields signify an attention-grabbing, illuminating, and crucial facet of foreign or second language learning and research. Forty-five (males and females) participants have been randomly chosen and participated in the experiment in Islamic Azad University, Zanjan, Iran, in 2014-2015 school year. The participants' age was between from 18 to 28 , with a mean age of 21.5 years. The materials were divided into two groups which include 30 true cognates and 30 false cognates words from 300 words by doing CVR (content validity ratio) and CVI (content validity index) (Lawshe's table with index of $88 \%$ and $82 \%$ respectively) for being reliable and valid. These words have been taught to them, after a week, a test has been prepared about those words. According to the results of T-test for comparing the average marks of learning in every two groups can be said that there is a meaningful difference between the scores. The results show that the students learned true cognate words better than the false cognate words. The results of this investigation conjointly make sure the expectations that cognate-based instruction can absolutely impact in second language acquisition.
\end{abstract}

Keywords: false and true cognates, L2 structural relationship, second language vocabulary acquisition, teaching through cognates

\section{Introduction}

Learning a word in a second language (L2) sometimes comprises relating a new philological form with a remaining thought is associated to the comparable word in the language. How this planning is recognized and the way it changes during time are serious matters in Second Language Acquisition (SLA), and above all within the vocabulary

\section{Lexis Acquisition Ground}

In spite of a number of analyses ripened to reply these queries (e.g., Basnight \& Altarriba, 2007; Bassetti

Javad Gholami, assistant professor, Ph.D., Department of English Language and Literature, Faculty of Humanities and Letters, Urmia University.

Parviz Alavinia, assistant professor, Ph.D., Department of English Language and Literature, Faculty of Humanities and Letters, Urmia University.

Siros Izadpanah, Ph.D. candidate, Department of English Language and Literature, Faculty of Humanities and Letters, Urmia University. 
\& Cook, 2011; Bultena, Dijkstra, \& van Hell, 2014; Casaponsa, Antón, Pérez, Dunabeitia, \&Mikeletegi, 2015; Ferré, Sánchez-Casas, \& Guasch, 2006; Guasch, Sánchez-Casas, Ferré, \& García-Albea, 2008; Kroll \& Linck, 2007; Sunderman \& Kroll, 2006), they are still object of controversy.

One of the foremost powerful prototypes within the SLA area is the Revised Hierarchic Model (RHM) by Kroll and Stewart (1994). The prototype reflects polyglot memory association as comprised of three unified structures: two independent words (L1 and L2) and a unified abstract structure combined by the two languages. A major characteristic of RHM is the concept that associations between the two vocabularies and the abstract system transform along with L2 expertise. Lecturers, polyglots, and psycholinguists have continually been enthusiastic about slips made by second language learners, either in their speaking or inscription, or together.

Studies on the false cognate trends are rather rare (Chacón, 2006). Investigations present that nearly all language manipulators of languages are fed up and mystified in figuring out those languages which share joint qualities in reverse. Additionally, they are less undoubtedly to study.

In the psycholinguistic literature, cognates are often defined as words that combine features of orthography, phonology, and meaning beyond languages (e.g., Setereh in Persian and Star in English). Second language (L2) learners are often fast to benefit from the resemblances discovered in cognates and handover knowledge from their first language (L1) to accelerate lexicon acquisition and perceiving within the L2.

The aim of the current study is to research in what way understanding of antecedently learned words can be used in L2. In particular, it tries to prove whether mentioning the similarities between the L1 and L2 vocabulary items can heighten L2 vocabulary acquisition. For this goal, an English vocabulary test was done among Iranian students whose L1 is Persian and who are learning English as an L2. Sometimes learners come across words in an L2 that are akin in style to those in their L1, but do not have share meaning (i.e., false cognates such as did signifying "doing a work" in English but in Persian representing "seeing").

The fact that nonnative cognate words are recognized and generated faster and more precisely than nonnative non-cognate words (Bultena, Dijkstra, \& van Hell, 2014; Midgley, Holcomb, \& Grainger, 2011; Peeters, Dijkstra, \& Grainger, 2013).

\section{Research Question}

Builton the assumption following L2 acquisition, the current study tries to depend on the outcomes of L1 acquisition studies regarding the process of learning foreign language lexis within cognates and to fulfill these in an L2 acquisition framework. Consequently, the basic question which the current investigation proposes to reply is: Do the Iranian students learn and remember true cognates or false cognates?

The expectations are that the students who imagine structural associations between L1 and L2 cognate pairs will learn well. As much as other factors are involved, the adeptness in L2 is predicted to show a crucial responsibility in L2 vocabulary skill.

\section{Literature Review}

A cognate is "a word in one language which is comparable in style and meaning to a word in another language because both languages are associated" (Richards \& Schmidt, 2002; Wright, Dobson, \& Sears, 2014). Cognates can share phonological and/or orthographic form, and are normally interconnected meaningfully though they are not continuously translation equals (Comesaña, Fraga, Moreira, Frade, \& Soares, 2014; Hall, 2002 ). Rodriguez (2001) cites various types of cognates which include words that are phonologically akin and 
orthographically identical (dental-dental); phonologically similar but orthographically different (velocity-velocidad), and false friends in which words are phonologically and orthographically similar but not related in meaning, such as, tan (in Persian and English). Bilingual speakers rate cognate translation pairs as more similar phonologically and orthographically than translation pairs that are not cognates (de Groot \& Nas, 1991; Elgort \& Piasecki, 2014). Monolingual speakers are more likely to correctly guess the meaning of the cognate pairs when asked to translate words in an unfamiliar language (Comesaña, Soares, Sánchez-Casas, \& Lima, 2012; Friel \& Kennison, 2001; Kroll \& Stewart, 1994).

Cognates are interesting to consider in the study of bilingual language acquisition and language disorders because of their similarity across languages. First, the process of learning cognates might differ from learning other words because learners can draw directly on their knowledge in one language to facilitate word learning in the other language. In vocabulary tests where vocabulary is ordered developmentally or by frequency, the level of item difficulty for bilingual children might differ compared to monolingual children (Dégi, 2012; Hall, Newbrand, Ecke, Sperr, Marchand, \& Hayes, 2009). Thus, the focus of this paper is on bilingual students' performance on true and false cognates learning task. We consequently see that though the cognate's cross-language intersection in philological style can ease bilingual word identification, any difference or nonequivalence in meaning can lead to sluggish processing.

\section{Cognates and False Cognates}

The degree of semantic and/or orthographic intersection between words is numerous. Languages are expected to smooth or affect with the communication of the planned messages. In circumstances where acceleration usually arise sat the philological level, scholars very frequently remark cognates defined as words that hold the same or a similar form and meaning in two or more natural languages (e.g., English brother and Barder in Persian). This type of words is conveyed to be rather routine, particularly when the two languages are from the same language family, or somehow associated (Chamizo \& Nerlich, 2002; Friel \& Kennison, 2001). When two words from diverse languages are identical or a similar form but do not share the same meaning, there takes place the instance of false cognates, also known as interlingual homographs or false friends in literature (e.g., dam in English and Persian ).

Meara (1993), Joshi and Aaron (2013) mentioned that false cognates are of attention to educators since they will produce problems for second language learners. Chamizo Dominguez and Nerlich (2002) divided false cognates into two groups, namely chance false friends (words that are similar or equivalent in two or more languages, but without any semantic or etymological overlap) and semantic false friends (words that are graphically and/or phonetically similar in various languages and having the same etymological origin, but the meanings of which have diverged). They also divided semantic false cognates as full false friends (words the meaning of which diverge widely in various languages) and partial false friends (words that have several senses, some of which coincide in both languages while others do not).

\section{Cognates and Vocabulary Learning}

Adults who are learning English as a second language slowly change from mediating their knowledge of words in their second language via their knowledge of words in their first language to having direct access between words and concepts in both of their languages (Dijkstra \& Rekké, 2010; Kroll \& Tokowicz, 2005). When this model is applied to the students of second language learning, we assume that when a student hears a 
new word such as spinach in English, they are most likely to access the concept via the first language (e.g., spheng in Persian) than directly access the concept via English language knowledge.

Phonological representations play a role in building this richer representation and ease lexical retrieval (Dressler, Carlo, Snow, August, \& White, 2011; Hoshino \& Kroll, 2008). In this study, phonologically similar words were regained more slowly than phonologically dissimilar words. At the same time cognates were produced more precisely. In the case of cognates such as these, English language learners can use their Persian vocabulary knowledge to recognize, understand, and practice English vocabulary (August, Carlo, Dressler, \& Snow, 2005; Peeters, Dijkstra, \& Grainger, 2013). English and Persian are connected because an important number of words in each language are Latin-based and consequently share a large number of cognate pairs (Comesaña, Ferré, Sáchez-Casas, Fraga, Soares, Rauber, \& Romero, 2013; Zare \& Mobarakeh, 2013; Pishghadam \& Khajavy, 2013). This increases occasions to use cognates as a device for language transfer. Cognates rise as students' progress scholastically.

Students can learn to use cognates as vocabulary learning strategy (Bravo, Hiebert, \& Pearson, 2007; Proctor \& Mo, 2011 ). In these studies, students learned about cognates via direct teaching (e.g., Proctor \& Mo, 2011) or by learning to look for resemblances (e.g., Bravo, Hiebert, \& Pearson, 2007). Following interferences of this style, students confirmed post test rises in their vocabulary scores (e.g., Grasso, 2014) and were able to use this knowledge to lessons and in reading comprehension (e.g., Bravo, Hiebert, \& Pearson, 2007).

\section{Teaching Vocabulary Through Cognates}

The curuent study tries to realize how the above-mentioned features can be carried out in foreign language vocabulary teaching in the background, where lesser students learn their first foreign language as an L2 after having acquired the state's language as an L1.

Contrary to the current, Jessner (2003) advocates that previous language information ought to be revitalized within the classroom which students ought to hunt for equivalent illustrations in their L1 and L2. In arrangement with Habash, Rambow and Tomeh (2013), Molnar (2010) regards it useful to teach students to draw on their cognate knowledge, which may function a way of deciding the meanings of recent English words Rodríguez (2001) proposes that English may be educated through meaningful reading and by relying on the students' knowledge and literacy in their L1. He additionally suggests that academic sought to admit L1/L2 cognates to show students to investigate the $\mathrm{L} 2$ and be ready to perceive texts within the L2.

Mitkov, Pekar, Blagoev, and Mulloni (2007) did a research among Spanish learning English who had been educated to look for cognate associations as a strategy in reading texts in English. The results of the study displayed that those students who were taught to search for cognate relationships were more successful in supposing meaning for untaught cognates than their peers in the control group.

Caplan-Carbin (2006),Van Assche, Duyck, and Hartsuiker (2012) suggested that teaching the systematic relationship of the historical sound changes between English and German would facilitate English speaking learners of German to distinguish cognates and as a result expand their vocabulary in German more simply.

\section{The Cognate Effect}

The literature on cognates, within both the SLA and bilingual lexicon research traditions, reveals a broad consensus that words that share an orthographic and/or phonological form across languages have different effects on learning, representation, and processing than pairs of words that do not share such properties. A distinction is often drawn between cognates that share meaning (either "true cognates", "indirect cognates", or 
those that do not share meaning called "false cognates", "falsefriends", or "interlingual homographs"). In SLA, it has been long recognized that cognates trigger cross linguistic influence: either "positive transfer" in the case of true cognates or "negative transfer" in the case of indirect and false cognates (Meara, 1993; Nation, 1990; Odlin, 2004; Ringbom, 1987; cf. also Friel \& Kennison, 2001, for a review of the research and a discussion of cognate identification procedures). Early experimental research on cognate representation and processing in bilinguals (e.g., de Groot, 1993; Kroll \& Stewart, 1994) appeared to demonstrate that true cognates, but not false cognates, are accessed, named, and translated faster than noncognates. Recent work on learners and balanced bilinguals, however, has demonstrated that sets of words that share an orthographic and/or phonological form interlingually are automatically activated at some point in both production and comprehension, regardless of meaning (Costa, Colom'e, G'omez, \& Sebasti'an-Gall'es, 2003; Hall, 2002).

Cognates also play a significant role in the organization of lexical competence and the linguistic performance of multilinguals. De Angelis and Selinker (2001) presented interlanguage samples from case studies of two multilinguals, which clearly prove CLI (cross linguistics influence) at the form level. van Hell and Dijkstra (2002) reported word association and lexical decision results on L1 Dutch words, using English L1 and French L2 words as peaks. They found a cognate effect for L1 in both tasks and an effect for L2 when participants' expertise level in French was as high as it was for English. Herwig (2001) reported data from think-aloud protocols that reveal a strong reliance on cognate forms in a translation task involving speakers of four languages. Similar findings were reported by Gibson and Hufeisen (2003), who collected qualitative data from learners who were asked to translate from a new L3 (Swedish) into their L2. Finally, comparative data on L3 learner English from Swedish native speakers with L2 Finnish and Finnish native speakers with L2 Swedish show clear cognate effects from Swedish to English (Odlin \& Jarvis, 2004).

Assuming a cognitive architecture that postulates spreading activation in a cross linguistic lexical network (Herwig, 2001; Kroll \& de Groot, 1997), these findings suggest that activation paths are regularly forged between lexical form representations that overlap at some criteria level. CLI at the lexical level may thus be understood as the establishment of interlingual connections of this type during acquisition and use of a second or subsequent language.

\section{Method}

Forty-five (males and females) participants from the Islamic Azad University of Zanjan, Iran, in 2014 have been randomly chosen and participated in the experiment. All participants were native speakers of Persian who were studying in term one in bachelor period. The participants' ages ranged from 18 to 25 , with an average age of 21.5 year. All participants were given a book for their participation in the study. Different dictionaries (Longman Dictionary of Contemporary English, Oxford Advanced Learner's Dictionary, Cambridge International Dictionary of English, and Collins Cobuild English Dictionary), internet, different sources were used in the project for the data collection. The materials were divided into two lists which include 30 true cognates and 30 false cognates words (phonological, orthographical, and semantic words) from 300 words and have been done CVR and CVI for being reliable and valid words. Due to the indo European language (Persian language), it was very difficult to find those words. These words have been taught to them and after a week, a test has been prepared about those words. With the help of T-test, the rates of memorizing true cognates and false cognates have been compared. The tested hypothesis has been as follows:

Hypothesis: There is a meaningful difference between the rate of memorizing true cognate and false 
cognate words. Hypothesis 0 and 1 for the test of comparing means in two samples are:

H0: The averages of two samples are equal. H1: The averages of the two samples are not equal.

In which $\mathrm{H} 1$ is the mean of true cognates in memorizing test and $\mathrm{H} 2$ is the average of marks of false cognate words in memorization test. Results of holding comparing marks of memorizing true cognate and false cognate are as follow (see Table 1):

Table 1

Comparing Mean of Two Group (True and False Cognate Words)

\begin{tabular}{|c|c|c|c|c|c|c|c|}
\hline \multirow[b]{2}{*}{ Test result } & \multicolumn{5}{|c|}{ T-test for comparing averages of 2 dependent groups } & \multirow{2}{*}{\multicolumn{2}{|c|}{ variable }} \\
\hline & Sig & d.f & $\mathrm{T}$ & Mean & Number & & \\
\hline Meaningful difference & 0.022 & 44 & 2.36 & $\begin{array}{l}13.5 \\
8.25\end{array}$ & $\begin{array}{l}45 \\
45\end{array}$ & $\begin{array}{l}\text { True cognates } \\
\text { False cognates }\end{array}$ & Memorizing words \\
\hline
\end{tabular}

According to the results of T-test for comparing the average marks of memorization in every two groups (true and false cognate words) can be said that there is a meaningful difference between the means. It means that between the rate of memorizing true and false cognate words, there is a meaningful difference so the average of marks on memorizing true cognate words is more than false cognate ones.

\section{Discussion and Conclusion}

The purpose of this study was to investigate whether instruction of the structural similarities between the L1 and L2 lexicon facilitates L2 vocabulary acquisition. The results showed that the students receiving such instruction obtained higher scores both on cognate target words than false cognates. Further analysis of the data revealed a positive correlation between L1 proficiency and the students' L2 vocabulary achievements. It was proposed that the method of teaching foreign language vocabulary through pointing out the similarities between the L1 and L2 lexical items is recommended because it may facilitate L2 vocabulary acquisition. Consistent with previous findings in the literature, and as expected, we found that individuals learned true cognates more quickly and accurately than false cognate words. The overlap of form and meaning across languages for the cognates facilitated lexical learning. Cognates were also considered as facilitating communication. Being aware of the true cognates or false friends, communication and learning are facilitated. As suggested by the current study, students' problems with false friends could be greatly reduced if teachers paid more attention to a meaningful teaching of these lexical items. False cognates or words that are pronounced and/or spelled the same in the two languages but do not mean the same thing, were also accessed significantly slower than true cognate. It is consistent with prior work demonstrating that cognate facilitation can be eliminated or reversed when there is not complete lexical overlap (Dijkstra, Grainger, \& van Heuven, 1999; Schwartz, Kroll, \& Diaz, 2007; Tokowicz \& Kroll, 2007). As expected, we found a significant cognate effect in a single-word presentation lexical decision task in the nonnative language, showing that cognate words were processed faster and more accurately than false cognate words in line with previous literature (Dijkstra, Miwa, Brummelhuis, Sappelli, \& Baayen, 2010; Dunabeitia, Perea, \& Carreiras, 2010; Midgley, Holcomb, \& Grainger, 2011; Peeters, Dijkstra, \& Grainger, 2013; Kassaian \& Esmae'li, 2011; Zare \& Mobarakeh, 2013; among others).

\section{Suggestions for Future Research}

As mentioned and highlighted in this paper, there are very few studied on the study of false friends in 
English and Farsi language. Given the existence of rather big gaps in this area of literature, more research needs to be directed by Iranian EFL (English as a Foreign Language) researchers to shed further light on this interesting and revelatory area of research. EFL/ESL (English as a Second Language) educators who have a high degree of familiarity with and proficiency in Farsi can also contribute to the enrichment of this area through research on it. Future research can focus not only on meaning-related, but also on etymological and pronunciational differences between false cognates of Farsi and English.

\section{References}

August, D., Carlo, M., Dressler, C., \& Snow, C. (2005). The critical role of vocabulary development for English language learners. Learning Disabilities Research and Practice, 20(1), 50-57.

Basnight, B. D. M., \& Altarriba, J. (2007). Differences in semantic and translation priming across languages: The role of language direction and language dominance. Memory \& Cognition, 35(5), 953-965.

Bassetti, B., \& Cook, V. (2011). Relating language and cognition: The second language user. Language and bilingual cognition, 143-190.

Bravo, M. A., Hiebert, E. H., \& Pearson, P. D. (2007). Tapping the linguistic resources of Spanish-English bilinguals. Vocabulary acquisition: Implications for reading comprehension, 140.

Bultena, S., Dijkstra, T., \& van Hell, J. G. (2014). Cognate effects in sentence context depend on word class, L2 proficiency, and task. The Quarterly Journal of Experimental Psychology, 67(6), 1214-1241.

Caplan-Carbin, L. (2006). Diachronic linguistics in the classroom: Sound shifts and cognate recognition. University of South Florida Fall 95/Seminar in Second Language Acquisition.

Casaponsa, A., Antón, E., Pérez, A., Dunabeitia, J. A., \& Mikeletegi, P. (2015). Foreign language comprehension achievement: Insights from the cognate facilitation effect. Name: Frontiers in Psychology, 6, 588.

Chacón, B. R. (2006). Towards a typological classification of false friends (Spanish-English). Revista Española de Lingüistica Aplicada, 19, 29-39.

Chamizo, D. P. J., \& Nerlich, B. (2002). False friends: Their origin and semantics in some selected languages. Journal of Pragmatics, 34, 1833-1849.

Chen, H. C., \& Leung, Y. S. (1989). Patterns of lexical processing in a non-native language. Journal of Experimental Psychology: Learning, Memory and Cognition, 15, 316-325.

Comesaña, M., Fraga, I., Moreira, A. J., Frade, C. S., \& Soares, A. P. (2014). Free associate norms for 139 European Portuguese words for children from different age groups. Behavior research methods, 46(2), 564-574.

Comesaña, M., Soares, A. P., Sánchez-Casas, R., \& Lima, C. (2012). Lexical and semantic representations of L2 cognate and non-cognate words acquisition in children: Evidence from two learning methods. Br J Psychol, 103(3), 378-92. doi: $10.1111 / \mathrm{j} .2044-8295$

Comesaña, M., Ferré, P., Sáchez-Casas, R., Fraga, I., Soares, A. P., Rauber, A., \& Romero, J. (2013). The contribution of phonology to visual cognate word recognition: Is it modulated by second language exposure? Paper presented at the 9th Symposium of Bilingualism, Singapore.

Costa, A., Colom'e, A., G'omez, O., \& Sebasti'an-Gall'es, N. (2003). Another look at cross-language competition in bilingual speech production: Lexical and phonological factors. Bilingualism: Language and Cognition, 6, 167-179.

De Angelis, G., \& Selinker, L. (2001). Interlanguage transfer and competing linguistic systems in the multilingual mind. In J. Cenoz, B. Hufeisen, \& U. Jessner (Eds.), Cross-linguistic influence in third language acquisition: Psycholinguistic perspectives (pp. 42-58). Clevedon, UK: Multilingual Matters.

Dégi, Z. (2012). Types of multilingualism explored in the Transylvanian school context. Jezikoslovlje, 13(2), 645-666.

De Groot, A. M., \& Nas, G. L. (1991). Lexical representation of cognates and non-cognates in compound bilinguals. Journal of memory and language, 30(1), 90-123.

De Groot, A. M. B. (1993). Word-type effects in bilingual processing tasks: Support for a mixed-representational system. In R. Schreuder \& B. Weltens (Eds.), The bilingual lexicon (pp. 27-51). Amsterdam: Benjamins.

Dijkstra, T., Miwa, K., Brummelhuis, B., Sappelli, M., \& Baayen, H. (2010). How Cross language similarity and task demands affect cognate recognition. J Mem Lang, 62(3), 284-301. doi: 10.1016/j.jml.2009.12.003

Dijkstra, T., \& van Heuven, W. J. B. (2002). The architecture of the bilingual word recognition system: From identification to 
decision. Bilingualism: Language and Cognition, 5, 175-197.

Dijkstra, T., \& Rekké, S. (2010). Towards a localist-connectionist model of word translation. The Mental Lexicon, 5, 401-420.

Dressler, C., Carlo, M. S., Snow, C. E., August, D., \& White, C. E. (2011). Spanish-speaking students' use of cognate knowledge to infer the meaning of English words. Bilingualism: Language and cognition, 14(02), 243-255.

Dunabeitia, J. A., Perea, M., \& Carreiras, M. (2010). Masked translation priming effects with 31 highly proficient simultaneous bilinguals. ExpPsychol, 57(2), 98-107. doi: 10.1027/1618-32 3169/a000013

Elgort, I., \& Piasecki, A. E. (2014). The effect of a bilingual learning mode on the establishment of lexical semantic representations in the L2. Bilingualism: Language and Cognition, 17(03), 572-588.

Eskander, R., Habash, N., Rambow, O., \& Tomeh, N. (2013). Processing spontaneous orthography. HLT-NAACL, 585-595.

Ferré, P., Sánchez-Casas, R., \& Guasch, M. (2006). Can a horse be a donkey? Semantic and form interference effects in translation recognition in early and late proficient and non-proficient Spanish-Catalan bilinguals. Language Learning, 56, 571-608.

Friel, B. M., \& Kennison, S. M. (2001). Identifying German-English cognates, false cognates, and non-cognates: Methodological issues and descriptive norms. Bilingualism: Language and Cognition, 4(03), 249-274.

Grainger J., Midgley, K., \& Holcomb, P. J. (2010). Re-thinking the bilingual interactive-activation model from a developmental perspective (BIA-d). In M. Kail \& M. Hickmann, Language acquisition across linguistic and cognitive systems (pp. 267-284). New York: John Benjamins.

Guasch, M., Sánchez-Casas, R., Ferré, P., \& García-Albea, J. E. (2008). Translation performance of beginning, intermediate and proficient Spanish-Catalan bilinguals. Effects of form and semantic relations. The Mental lexicon, 3, 289-308.

Gibson, M., Hufeisen, B., \& Libben, G. (2001). Learners of German as an L3 and Their production of German prepositional verbs. In J. Cenoz, B. Hufeisen, \& U. Jessner (Eds.), Cross-linguistic influence in third language acquisition: Psycholinguistic perspectives (pp. 90-114). Clevedon, UK: Multilingual Matters.

Grasso, S. M. (2014). A cross-linguistic comparison of cognate production in bilingual children with and without language impairment (Doctoral dissertation, the University of Texas at Austin).

Hall, C. J., Newbrand, D., Ecke, P., Sperr, U., Marchand, V., \& Hayes, L. (2009). Learners' implicit assumptions about syntactic frames in new L3 words: The role of cognates, typological proximity, and L2 status. Language Learning, 59(1), 153-202.

Hall, C. J. (2002). The automatic cognate form assumption: Evidence for the Parasitic Model of vocabulary development. International Review of Applied Linguistics, 40, 69-87.

Herwig, A. (2001). Plurilingual lexical organisation: Evidence from lexical processing in L1-L2-L3-L4 translation. In J. Cenoz, B. Hufeisen, \& U. Jessner (Eds.), Cross-linguistic influence in third language acquisition: Psycholinguistic perspectives (pp. 115-137). Clevedon, UK: Multilingual Matters.

Hoshino, N., \& Kroll, J. F. (2008). Cognate effects in picture naming: Does cross-language activation survive a change of script? Cognition, 106(1), 501-511.

Jessner, U. (2003). The nature of cross-linguistic interaction in the multilingual system. The multilingual lexico, 45-55. doi: 10.1007/978-0-306-48367-7_4

Kassaian, Z., \& Esmae'li, S. (2011). The effect of bilinguality on L3 breadth of vocabulary knowledge and word reading skill. Theory and Practice in Language Studies, 1(8), 966-974. doi: 10.4304/tpls.1.8.966-974

Kroll, J. F., \& Linck, J. A. (2007). Representation and skill in second language learners and proficient bilinguals. In I. Kecskes \& L. Albertazzi (Eds.), Cognitive aspects of bilingualism (pp. 237-269). New York: Springer.

Kroll, J. F., \& Stewart, E. (1994). Category interference in translation and picture naming: Evidence for asymmetric connections between bilingual memory representations. Journal of Memory and Language, 33, 149-174.

Kroll, J. F., \& Tokowicz, N. (2005). Models of bilingual representation and processing: Looking back and to the future. In J. Kroll \& A. De Groot (Eds.). Handbook of bilingualism: Psycholingustic approaches (pp. 531-554). Oxford, UK: Oxford University Press.

Lawshe, C. H. (1975). A qualitative approach to content validity. Personnel Psychology, 28 (4), 563-575.

Meara, P. (1993). The bilingual lexicon and the teaching of vocabulary. In R. Schreuder \& B. Weltens (Eds.), The bilingual lexicon (pp. 279-297). Philadelphia: John Benjamins.

Midgley, K. J., Holcomb, P. J., \& Grainger, J. (2011). Effects of cognate status on word 8 comprehension in second language learners: An ERP investigation. J Cogn Neurosci, 23(7), 1634-1647. doi: 10.1162/jocn.2010.21463

Mitkov, R., Pekar, V., Blagoev, D., \& Mulloni, A. (2007). Methods for extracting and classifying pairs of cognates and false friends. Machine translation, 21(1), 29-53. 
Molnar, T. (2010). Cognate recognition and L3 vocabulary acquisition. Act a Universitatis Sapientiae Philologica, 2.2, $337-349$.

Nagy, W. E., Garcia, G.B., Durgunoglu, A, \& Hancin-Bhatt, B. (1992). Cross-language transfer of lexical knowledge: Bilingual students' use of cognates. Urbana, IL: Urbana Center for the Study of Reading.

Odlin, T., \& Jarvis, S. (2004). Same source, different outcomes: A study of Swedish influence on the acquisition of English in Finland. International Journal of Multilingualism, 1, 123-140.

Peeters, D., Dijkstra, T., \& Grainger, J. (2013). The representation and processing of identical 18 cognates by late bilinguals: RT and ERP effects. J Mem Lang, 68(4), 315-332. doi: 19 10.1016/j.jml.2012.12.003

Pishghadam, R., \& Khajavy, G. H. (2013). Intelligence and metacognition as predictors of foreign language achievement: A structural equation modeling approach. Learn Individ Differ, 24, 176-181. doi: 10.1016/j.lindif.2012.12.004

Proctor, C. P., Dalton, B., Uccelli, P., Biancarosa, G., Mo, E., Snow, C., \& Neugebauer, S. (2011). Improving comprehension online: Effects of deep vocabulary instruction with bilingual and monolingual fifth graders. Reading and Writing, 24(5), 517-544.

Richards, J. C., \& Schmidt, R. (2002). Longman dictionary of applied linguistics and language teaching (3rd ed.). Harlow, UK: Longman.

Wright, C. A., Dobson, K. S., \& Sears, C. R. (2014). Does a high working memory capacity attenuate the negative impact of trait anxiety on attentional control? Evidence from the antisaccade task. Journal of Cognitive Psychology, 26(4), 400-412.

Ringbom, H. (2001). Lexical transfer in L3 production. In J. Cenoz, B. Hufeisen, \& U. Jessner (Eds.), Cross-linguistic influence in third language acquisition: Psycholinguistic perspectives (pp. 59-68). Clevedon: Multilingual Matters.

Rodriguez, T. A. (2001). From the known to the unknown: Using cognates to teach English to Spanish-speaking literates. The Reading Teacher, 744-746.

Schwartz, A. I., Kroll, J. F., \& Diaz, M. (2007). Reading words in Spanish and English: Mapping orthography to phonology in two languages. Language and Cognitive Processes, 22, 106-129.

Sunderman, G., \& Kroll, J. F. (2006). First language activation during second language lexical processing: An investigation of lexical form, meaning, and grammatical class. Studies in Second Language Acquisition, 28, 387-422.

Tokowicz, N., \& Kroll, J. F. (2007). Number of meanings and concreteness: Consequences of ambiguity within and across languages. Language and Cognitive Processes, 22, 727-779.

Zare, M., \& Mobarakeh, S. D. (2013). Effects of bilingualism on L3 vocabulary learning among Iranian EFL learners. GEMA Online Journal of Language Studies, 13(1), 127-138.

Van Assche, E., Duyck, W., \& Hartsuiker, R. J. (2012). Bilingual word recognition in a sentence context. Frontiers in psychology, 3. 